\title{
Alternative Tobacco Products Use among Late Adolescents in Kelantan, Malaysia
}

\author{
Nurul Azreen Yusof, Faridah Mohd Zin*, Nur Suhaila Idris, Rosediani Mohammad \\ Department of Family Medicine, School of Medical Sciences, Universiti Sains Malaysia, Kelantan, Malaysia
}

Background: The rising prevalence of alternative tobacco and nicotine products (ATNPs) use among adolescents is a global concern that has been attributed to the reemergence of preexisting alternative tobacco products and emergence of new ones in the market. This study examined ATNP use among late adolescents. The association between ATNP use and reasons for using them was explored.

Methods: This cross-sectional study conducted in 2016 involving 388 late adolescents from six government colleges in Kelantan, Malaysia, aged 18 to 19 years. They were requested to answer self-directed questionnaires with items on sociodemographic information and types of ATNP used. Other variables obtained include the environmental influence and reasons for using the products. Regression analyses between the dependent and independent variables were conducted using IBM SPSS ver. 20.0 (IBM Corp., Armonk, NY, USA).

Results: The prevalence of ATNP use among late adolescents was $14.4 \%$. The male sex, cigarette smoking status, and peer use were significantly associated with ATNP use. Several reasons for use were not significantly associated with ATNP use: perception of ATNP being less harmful and less addictive compared with cigarettes, curiosity, less expensive than cigarettes, to aid smoking cessation, and pleasurable flavors and taste.

Conclusion: The prevalence of ATNP use among late adolescents studying in government colleges in Kelantan is significant. There is higher perception on ATNP being less harmful and addictive than the conventional cigarette among the users compared with non-users. Significant associations are seen for the male sex, peer use, and concurrent cigarette smoking.

Keywords: Tobacco; Nicotine; Adolescent; Demographic; Reason for Using

Received: February 5, 2018, Revised: May 18, 2018, Accepted: June 8, 2018

${ }^{*}$ Corresponding Author: Faridah Mohd Zin https://orcid.org/0000-0002-7014-4347

Tel: +60-9-7676612, Fax: +60-9-7673370, E-mail: faridahz@usm.my 


\section{INTRODUCTION}

Tobacco products have undergone transformation in the style of consumption. Traditionally, they have been used as conventional cigarettes or older form of smoked tobacco and smokeless tobacco. Smoked tobacco includes the manufactured cigarette, hand-rolled cigarette, kretek (clove), tobacco-filled pipe, cigar or cigarillo, shisha or hookah, and bidi. ${ }^{1)}$ The smokeless tobacco involves direct use of tobacco either by nasal sniffing, keeping it in the mouth, or chewing. ${ }^{1)}$ Since the last decade, tobacco use has gone through an evolutionary change from conventional manufactured cigarettes to alternative tobacco and nicotine products (ATNP).

Two notable transitions seen in the tobacco market are the re-emergence of the shisha and the latest electronic nicotine delivery device called the electronic cigarette (e-cigarette). Apart from the electronic device, other forms of tobacco consumption deliver higher doses of tar, nicotine, and carbon monoxide, all associated with adverse health effects, including cancers, chronic obstructive pulmonary disease, cardiovascular diseases, and nicotine addiction. ${ }^{2)}$ The distinctive features of the shisha are the aromatic tobacco used, easy availability, and attractive designs, all of which would have contributed to its popularity. ${ }^{3)}$ The levels of nicotine and cotinine in shisha smokers have been found to be high after only one session of hookah (shisha) use. ${ }^{4)}$ Although limited research has been done on the health risks of shisha use, evidence from previous studies indicates that it poses similar health risks as cigarette smoking. ${ }^{5)}$ The second transition was the emergence of vaporized nicotine products, introduced in 2003: the e-cigarette, ${ }^{6,7)}$ which is consumed through 'vaping. ${ }^{\prime 8)}$ These devices, often designed to resemble cigarettes, work by vaporizing a solution containing nicotine dissolved with flavoring in propylene glycol. ${ }^{5}$ Meanwhile, older tobacco products, such as smokeless tobacco, kretek, cigar, tobacco chewing, tobacco snuff, hand-rolled cigarettes, and pipes, which are thought to be less popular among the youth, are being used in a small percentage, as reported in a Malaysian youth survey. ${ }^{3)}$

Many smokers have changed their smoking habit to vaping, as the ecigarette has been marketed as cheaper and safer, and as a possible smoking cessation tool. ${ }^{8)}$ The nicotine delivery of the e-cigarettes has been tested to be significantly lower compared with cigarettes. ${ }^{5)}$ ATNP have been perceived as less toxic than regular cigarettes. ${ }^{9-11)}$ Among Malaysian smokers, substantial numbers have reported using e-cigarettes and shisha to quit smoking tobacco. ${ }^{11,12)}$ Other contributing factors include curiosity, especially in adolescents, ${ }^{10,13,14)}$ lower cost, ${ }^{9,11,12,15-18)}$ and pleasurable flavor. ${ }^{3,9,18,19)}$

With the increasing popularity of these products, local research should be carried out to determine the significance of this issue affecting the younger generations. The present research is expected to contribute to the body of knowledge on the factors encouraging young users to choose these products. The findings may also facilitate the strengthening of local tobacco and nicotine control and subsequently mitigating its destructive health effects. This paper reports the prevalence of ATNP use among late adolescents attending colleges in Kelan- tan, Malaysia, and its association with their reasons for using and sociodemographic characteristics.

\section{METHODS}

This cross-sectional study was conducted among college students aged 18 to 19 years in 2016. College students were chosen to ensure homonymous environmental exposure. The sample size was reached using the single proportion formula. The calculated sample size was 388 to meet a statistical power of $80 \%$, absolute precision of less than 0.05 , and consideration for a $20 \%$ non-response rate with the percentage of ATNP use among adolescents from the Institute for Public Health in 2016. The sample sizes calculated for the independent variables, using 'Power and Sample Size' calculation software, were lower than the former and thus inadequate to show statistical difference. Thus, the sample size from the former calculation was used in this study. From 15 government colleges in the district, we selected six colleges using simple random sampling to achieve the required sample size. Subsequently, convenient sampling was applied, in which all students in the late adolescent age group were included. Students voluntarily participated in this study; informed consent was requested for them to answer the set of research questionnaires. The participants needed approximately 15 to 20 minutes to complete the self-directed questionnaire. This study was approved by the Human Research Ethical Committee of Universiti Sains Malaysia (JPeM/15130696).

The study material composed of a set of questionnaires with two sections. Section A consisted of five questions on sociodemographic characteristics (sex, race, religion, household income, peer use, sibling use, parents' use). Section B consisted of background of ATNP usage (two items), associated factors, and reasons for ATNP use (eight items). The questions were adapted from the International Tobacco Control Project in 2012 and Global Youth Tobacco Survey Questionnaire by the World Health Organization in 2012. The items on background of ATNP use included dichotomous questions on previous use and type of products used. The items on associated factors included peer use, parents' use, and siblings' use, whereas items on reasons for ATNP use were their perceptions on ATNP being less harmful and less addictive than the conventional cigarette, curiosity, as smoking cessation aid, variety of flavors, and cheaper price (Table 1).

The data were descriptively analyzed using IBM SPSS ver. 22.0 (IBM Corp., Armonk, NY, USA) for the prevalence of ATNP use. The association between the dependent variable (ATNP use) and independent variables (sociodemographic characteristics and reasons for using ATNP) was determined using the same software for logistic regression. Simple logistic regression was used for screening in the selection of variables whereby all variables with P-value of less than 0.05 and clinically significant variables were then included in multiple logistic regression. Variable selection was done using the backward and forward procedures where the selection of variables was based on the Wald test. This process of deleting, refitting, and verifying continued until all of the important variables were included in the model and those ex- 
cluded were clinically and/or statistically unimportant. In this step, the preliminary main effect model was obtained. All possible two-way interactions were checked; significant variables were included in the model. The independent variables were fitted into multiple logistic re-

Table 1. Associated factors of ATNP use by simple logistic regression

\begin{tabular}{|c|c|c|c|}
\hline Variable & $\begin{array}{l}\text { Wald } \\
\text { statistic }\end{array}$ & $\begin{array}{c}\text { Crude odds ratio } \\
\text { (95\% confidence interval) }\end{array}$ & P-value \\
\hline \multicolumn{4}{|l|}{ Sex } \\
\hline Male & 54.79 & 1.00 & \\
\hline Female & & $25.70(10.88-60.71)$ & $<0.001$ \\
\hline \multicolumn{4}{|l|}{ Peer use } \\
\hline Yes & 102.76 & 1.00 & \\
\hline No & & $19.93(11.18-35.55)$ & $<0.001$ \\
\hline \multicolumn{4}{|l|}{ Parents' use } \\
\hline Yes & 3.78 & 1.00 & \\
\hline No & & $2.36(0.99-5.61)$ & 0.052 \\
\hline \multicolumn{4}{|l|}{ Sibling use } \\
\hline Yes & 0.43 & 1.00 & \\
\hline No & & $1.23(0.66-2.29)$ & 0.510 \\
\hline \multicolumn{4}{|c|}{ ATNP perceived as less harmful } \\
\hline Yes & & 1.00 & \\
\hline No & 7.04 & $2.39(1.26-4.57)$ & 0.008 \\
\hline Don't know & 7.39 & $1.03(0.63-1.68)$ & 0.906 \\
\hline \multicolumn{4}{|c|}{ ATNP perceived as less addictive } \\
\hline Yes & & 1.00 & \\
\hline No & 9.94 & $2.81(1.48-5.35)$ & 0.002 \\
\hline Don't know & 0.92 & $0.77(0.46-1.31)$ & 0.339 \\
\hline \multicolumn{4}{|c|}{ Concurrent cigarette smoking } \\
\hline Yes & 114.99 & 1.00 & \\
\hline No & & 16.53 (9.89-27.59) & $<0.001$ \\
\hline \multicolumn{4}{|l|}{ Curiosity } \\
\hline Yes & 0.39 & 1.00 & \\
\hline No & & $1.17(0.71-1.92)$ & 0.532 \\
\hline \multicolumn{4}{|c|}{ To aid smoking cessation } \\
\hline Yes & 1.76 & 1.00 & \\
\hline No & & $1.33(0.87-2.05)$ & 0.185 \\
\hline \multicolumn{4}{|l|}{ Pleasurable flavors } \\
\hline Yes & 0.55 & 1.00 & \\
\hline No & & $1.17(0.78-1.76)$ & 0.459 \\
\hline \multicolumn{4}{|l|}{ Less expensive } \\
\hline Yes & 0.27 & 1.00 & \\
\hline No & & $0.89(0.58-1.37)$ & 0.601 \\
\hline
\end{tabular}

gression and variance inflation factors were obtained to check for multicollinearity. A preliminary final model was subsequently obtained.

Fitness of the model was tested by the Hosmer-Lemeshow goodness of fit test. The model fit perfectly if the P-value approached 1 . The classification table and receiver operating characteristic (ROC) curve were used to determine the fitness of the model. The high overall percentage in the classification table and area under the curve toward 1 in the ROC curve showed that the model was a good fit. Findings were presented with crude and adjusted odds ratio (OR), 95\% confidence interval (CI), and P-value. the level of significance was set at 0.05 with two-tailed fashion.

\section{RESULTS}

A total of 388 college students participated in this study with $100 \%$ response rate. Majority of the participants were male ( $\mathrm{n}=291,75.0 \%)$, and identified as Malay (99.5\%) and Muslims (99.5\%). The median (interquartile range) for parents' monthly income for users and nonusers were low at US dollar (USD) 293.22 (390.96) and USD 244.35 (293.22), respectively. The prevalence of ATNP use among college students in Kelantan was $14.4 \%$. The types of tobacco and nicotine products used according to ATNP user status are given in Table 2. The outcomes of the descriptive statistics and simple and multiple logistic regressions are tabulated in Tables 1 and 3, respectively.

In the final model, participants whose friends were ATNP users had an increased likelihood of using those products by 12 times compared with those whose friends were non-users (95\% CI, 5.82 to 26.52; $\mathrm{P}<0.001$ ). Males had increased odds (4.8 times) of being ATNP users compared with females (95\% CI, 1.73 to 13.13; $\mathrm{P}<0.002$ ). Further, those who smoked cigarettes were eight times more likely to use ATNP compared with non-smokers (95\% CI, 4.12 to 15.86 ; $\mathrm{P}<0.001$ ). The fitness of the model was shown by the non-significant Hosmer-Lemeshow goodness of fit test (0.931), high overall percentage in the classification table (84.0\%), and significant area under curve of the ROC curve (0.92). The final results of the multiple logistic regression are summarized in Table 4.

Table 2. Types of tobacco and nicotine products used according to alternative tobacco and nicotine products user status

\begin{tabular}{|c|c|c|c|c|c|}
\hline \multirow{3}{*}{ User status } & \multicolumn{5}{|c|}{ Types of tobacco used } \\
\hline & \multirow{2}{*}{ Manufactured cigarettes } & \multicolumn{4}{|c|}{ Alternative tobacco/nicotine products } \\
\hline & & E-cigarette & Shisha & Other smoked tobacco* & Any smokeless tobacco \\
\hline Current users ${ }^{\dagger}$ & $84(21.6)$ & $23(5.9)$ & $27(7.0)$ & $6(1.5)$ & 0 \\
\hline Previous users ${ }^{\ddagger}$ & $73(18.8)$ & $144(37.1)$ & $108(27.8)$ & $56(14.5)$ & $3(0.8)$ \\
\hline Non-users ${ }^{\S}$ & $231(59.6)$ & $221(57.0)$ & $253(65.2)$ & $326(84.0)$ & $384(99.2)$ \\
\hline
\end{tabular}

Values are presented as number (\%).

${ }^{*}$ Other smoked tobacco include bidi, kretek, cerut, cigarillo, and pipe (36). ${ }^{\top}$ Those who are current daily and current occasional users (less than daily) (36). ${ }^{\ddagger}$ Those who formerly used any form of alternative tobacco and nicotine products but currently not using them (36). ${ }^{\S}$ Those who never smoke or never used any form of alternative tobacco and nicotine products. 


\section{DISCUSSION}

Our results indicated that ATNP use among adolescents in Malaysia is a troublesome issue. Our finding of $14.4 \%$ current ATNP use exceeds

Table 3. Descriptive statistics of the associated factors of alternative tobacco and nicotine products use

\begin{tabular}{|c|c|c|c|}
\hline \multirow{2}{*}{ Variable } & \multirow{2}{*}{$\begin{array}{c}\text { Total } \\
(\mathrm{n}=388)\end{array}$} & \multicolumn{2}{|c|}{$\begin{array}{l}\text { Alternative tobacco/nicotine } \\
\text { products }\end{array}$} \\
\hline & & $\begin{array}{c}\text { Users } \\
(n=189)\end{array}$ & $\begin{array}{c}\text { Non-users } \\
(n=199)\end{array}$ \\
\hline \multicolumn{4}{|l|}{ Sex } \\
\hline Male & $291(75.0)$ & $183(96.8)$ & $108(54.3)$ \\
\hline Female & $97(25.0)$ & $6(3.2)$ & $91(45.7)$ \\
\hline \multicolumn{4}{|l|}{ Peer use } \\
\hline Yes & $239(61.6)$ & $172(91.0)$ & $67(33.7)$ \\
\hline No & $149(38.4)$ & $17(9.0)$ & $132(66.3)$ \\
\hline \multicolumn{4}{|l|}{ Parents' use } \\
\hline Yes & $25(6.4)$ & $17(9.0)$ & $8(4.0)$ \\
\hline No & $363(93.6)$ & $172(91.0)$ & $191(96.0)$ \\
\hline \multicolumn{4}{|l|}{ Sibling use } \\
\hline Yes & $46(11.9)$ & 25 (13.2) & $21(10.6)$ \\
\hline No & $342(88.1)$ & $164(86.8)$ & $178(89.4)$ \\
\hline \multicolumn{4}{|c|}{ ATNP perceived as less harmful } \\
\hline Yes & $65(16.7)$ & $43(22.8)$ & $22(11.1)$ \\
\hline No & $83(21.4)$ & $36(19.0)$ & $47(23.6)$ \\
\hline Don't know & $240(61.9)$ & $110(58.2)$ & $130(65.3)$ \\
\hline \multicolumn{4}{|c|}{ ATNP perceived as less addictive } \\
\hline Yes & $90(23.2)$ & $64(33.9)$ & $26(13.1)$ \\
\hline No & 77 (19.8) & $36(19.0)$ & $41(20.6)$ \\
\hline Don't know & $221(57.0)$ & $89(47.1)$ & $132(66.3)$ \\
\hline \multicolumn{4}{|c|}{ Concurrent cigarette smoking } \\
\hline Yes & $126(32.5)$ & $138(73.0)$ & $28(14.0)$ \\
\hline No & $262(67.5)$ & $51(27.0)$ & $171(86.0)$ \\
\hline \multicolumn{4}{|c|}{ To aid smoking cessation } \\
\hline Yes & 125 (32.2) & $67(35.4)$ & $58(29.1)$ \\
\hline No & $263(67.8)$ & $122(67.6)$ & $141(70.9)$ \\
\hline \multicolumn{4}{|l|}{ Curiosity } \\
\hline Yes & 309 (79.6) & $153(81.0)$ & $156(78.3)$ \\
\hline No & 79 (20.4) & $36(19.0)$ & $43(21.6)$ \\
\hline \multicolumn{4}{|l|}{ Pleasurable flavors } \\
\hline Yes & $237(61.1)$ & $119(63.0)$ & $118(59.3)$ \\
\hline No & $151(38.9)$ & $70(37.0)$ & $81(40.7)$ \\
\hline \multicolumn{4}{|l|}{ Less expensive } \\
\hline Yes & $124(32.0)$ & $58(30.7)$ & $67(33.7)$ \\
\hline No & $264(68.0)$ & 131 (69.3) & $132(66.3)$ \\
\hline
\end{tabular}

Values are presented as number (\%).

ATNP, alternative tobacco and nicotine products. that reported in the Malaysia Global Youth Tobacco Survey 2009 $(9.5 \%){ }^{20)}$ A lower prevalence was reported among adolescents and adults aged over 15 years in this region (2.0\%). ${ }^{1)}$ The significant increment in prevalence would have been contributed by the increasing popularity and accessibility of ATNP. Globally, more prevalent findings have been reported. Data from Global Youth Tobacco Survey conducted from 1999 to 2008 showed that $12 \%$ of boys and $8 \%$ of girls use ATNP, mainly among those living in Africa, Eastern Mediterranean countries, and Europe. ${ }^{21)}$ Further increment was observed among American Latin youth at $24.1 \%$, and $18.0 \%{ }^{22,23)}$

With respect to the types of ATNP, our study showed a much higher prevalence of e-cigarettes and shisha use compared with the other types of ATNP. Of the adolescents, $7.0 \%$ reported being current shisha users, with $27.8 \%$ of them having used shisha in the past. Meanwhile, $5.9 \%$ of the adolescents were current e-cigarette users and $37.1 \%$ were previous users. The Tobacco and E-cigarette Survey among Malaysian Adolescents 2016 (TECMA) reported that $9.1 \%$ of Malaysian adolescents and $7.8 \%$ of adolescents in Kelantan State reported current ecigarette use. ${ }^{3)}$ Although the prevalence found in our study is not comparable to the latter owing to the smaller study area, the finding supports the need for active intervention in combating this problem.

E-cigarettes have become a preferred alternative for nicotine delivery among smokers because of the realistic look, different feel of the smoke, and various tastes compared with manufactured cigarettes. Comparatively, the shisha is commonly used among adolescents despite being one of the oldest tobacco products to exist. The latest national survey reported a total of $3.5 \%$ of adolescents as current shisha users; previous shisha smokers accounted for $10.6 \% .^{3)}$ The increasing prevalence of ATNP use, especially of shisha and e-cigarettes, might be contributed by the commercialization through websites and social media, and increased accessibility through online purchase. Other contributing factors include the perception for shisha use as a part of the modern lifestyle, ${ }^{15)}$ culturally acceptable norms, and accessibility of shisha in public places, particularly in restaurants and cafés. ${ }^{17}$ Meanwhile, shisha allows people to spend a leisurely time with friends and family at cafés and bars. ${ }^{15)}$ It is also a growing threat to public health because of the common misconception that smoking shisha is relatively less hazardous than smoking cigarettes. Further, most of the outlets offering shisha remain largely unregulated. ${ }^{12)}$

The rates of previous shisha and e-cigarette users were higher compared with current users. The decrease may be attributed to the high rate of experimentation among adolescents and shared characteristics

Table 4. Associated factors to the use of alternative tobacco and nicotine products by multiple logistic regression

\begin{tabular}{|c|c|c|c|c|}
\hline Variable & Category & Adjusted odds ratio (95\% confidence interval) & Wald statistic & P-value \\
\hline \multirow[t]{2}{*}{ Sex } & Female & 1.00 & & \\
\hline & Male & $4.77(1.73-13.13)$ & 9.15 & 0.002 \\
\hline \multirow[t]{2}{*}{ Peer use } & No & 1.00 & & \\
\hline & Yes & $12.42(5.82-26.52)$ & 42.73 & $<0.001$ \\
\hline \multirow[t]{2}{*}{ Concurrent cigarette smoking } & No & 1.00 & & \\
\hline & Yes & $8.08(4.12-15.86)$ & 36.92 & $<0.001$ \\
\hline
\end{tabular}


of the products, such as availability of appealing and sweet flavors. The TECMA survey in 2016 also reported that $10.6 \%$ (95\% CI, 9.5 to 11.9) of adolescents had been offered a free trial of e-cigarette and $7.9 \%$ (95\% CI, 6.9 to 9.0) had been offered e-cigarette liquid by vendors. ${ }^{3)}$

Meanwhile, the National Youth Tobacco Survey conducted in the United States from 2011 to 2012 reported an overall prevalence of smokeless tobacco of only $6.4 \%{ }^{22)}$ This finding was also consistent with the findings of Enofe et al. ${ }^{23)}$ in 2014 and Czoli et al. ${ }^{6}$ in 2015. In contrast, we found a very low percentage of adolescents (1.5\%) who reported being current users of other smoked tobacco products such as bidi and kretek; none of them used smokeless tobacco. Moreover, $14.4 \%$ of them had tried other smoked tobacco, whereas $0.8 \%$ had used smokeless tobacco in the past. These findings might be due to the decreasing popularity of these products, perceived as old fashion and not in line with the current trend.

In the present study, male sex, peer use, and concurrent cigarette smoking were significant associated factors for ATNP use among late adolescents. The overall use of ATNP was 4.8 times more likely to occur among male students (OR, 4.8; 95\% CI, 1.73 to 13.13). Male students were predominantly involved in all types of ATNP, confirming previous studies that reported that male students had higher odds of being shisha and e-cigarette users compared with female students. ${ }^{15,24,25)}$ A local survey has also reported the same finding: more male adolescents used e-cigarettes, shisha, and the other types of tobacco products. ${ }^{3)}$ The acceptance of tobacco use as a social norm among men would be the main contributor. Women smokers would have more social pressure driven by cultural factors and community stigmatization. ${ }^{26,27)}$

The positive association between smoking status and e-cigarette use has been demonstrated in previous studies and the Malaysian National Survey (TECMA) in 2016. ${ }^{2,6,16,28)}$ The TECMA survey reported a prevalence of current dual users (e-cigarette and manufactured cigarette) of $5.2 \% .{ }^{3)}$ However, our result has shown a substantially higher percentage of dual users: $34.8 \%$ of current users were dual users; only $5.8 \%$ exclusively used ATNP. Students who smoke cigarettes were found to be eight times more likely to be using ATNP compared with non-smokers (OR, 8.08; 95\% CI, 4.12 to 15.86). The concurrent use of products causes almost similar addiction, as both contain nicotine, leading to a higher risk of dependence. ${ }^{29)}$

Peer use significantly influenced ATNP use among adolescents. Having more smoking friends and siblings predicted smoking initiation. ${ }^{26,30)}$ Another key finding of the present study is that those who have friends using ATNP have 12 times increased odds of using those products compared with those whose friends were non-users. In Malaysia, almost half of all adolescent current e-cigarette users obtained their e-cigarettes from friends, emphasizing the importance of friends' influence in this practice. Similar findings have been reported the other authors: having more friends who used alternative tobacco products significantly influenced one's use of tobacco leaves, cigars, and ecigarettes. ${ }^{2,29,31)}$ Peer influence is believed to be strengthened by the increase in promotion through social networking among Malaysian ado- lescents through social media.

In the present study, $22.8 \%$ of the users perceived ATNP as less harmful, whereas $33.9 \%$ perceived they were less addictive compared with conventional cigarettes. Our findings were much lower than the national data: $63.6 \%$ of Malaysian adolescents claimed that e-cigarettes are safer than tobacco cigarettes. ${ }^{3)}$ The misconception among adolescents who perceive shisha as not as harmful as conventional cigarettes was also demonstrated in previous studies. ${ }^{12,15,16,29,32)}$ The ecigarette is also thought to be less harmful than regular cigarettes, thereby being regarded as an alternative or replacement to decrease health risks. ${ }^{7)}$ Moreover, many studies have proven that ATNP users perceive the products as less addictive. . $^{15,16,18,33)}$

Because of these perceptions, $53.6 \%$ of ATNP users in the present study used the products to aid in smoking cessation. These misconceptions on the health risks are believed to be owing to poor knowledge and understanding of ATNP among adolescents. ${ }^{12)}$ ATNP use has been reported to be associated with lower odds of abstinence from cigarette smoking. ${ }^{34)}$ Despite the e-cigarette's touted potential to decrease cigarette consumption, empirical evidence shows that this device's help in smoking cessation is lacking. Studies have shown that the change in practice is not associated with successful quit attempts. ${ }^{35)}$ Hence, e-cigarette use would result in prolonged nicotine addiction instead of helping in smoking cessation. ${ }^{11)}$

The high percentage of ATNP users in our study tried ATNP because of their pleasurable flavors, curiosity, and less expensive price $(50.2 \%$, $49.5 \%$, and $46.8 \%$, respectively). A few authors have stated that the appealing smell and fruit-flavored taste were attractive elements for smokers to continue smoking shisha. ${ }^{16-18)}$ A similar finding has been reported for the e-cigarette. ${ }^{3,19)}$ Adolescents experiment with e-cigarettes and shisha owing to curiosity, as has also been clearly proven. ${ }^{9,10,14,19)}$ Such curiosity tends to be driven by observing the feeling of pleasure demonstrated by others while exhaling smoke with various aromas. ${ }^{14)}$ Both local and international studies have also reported that the price factor is significantly influential in adolescents choosing tobacco products, especially shisha and e-cigarettes., ${ }^{9,11,15,16,18)}$

A limitation of this study is that our samples might not represent the entire adolescent population in Kota Bharu, as the data were collected from only a few colleges in the Kota Bharu district of Kelantan. However, our study involved six out of 15 government colleges with adequate sample size that showed significant results at 0.05 with $80 \%$ statistical power.

In conclusion, ATNP use has become increasingly prevalent among adolescents. Male sex, peer use, and concurrent cigarette smoking are significantly associated with ATNP use among this group. Reasons for using include the perception of ATNP being less harmful and less addictive compared with conventional cigarettes. Other reasons for using are the pleasurable flavors, curiosity with, and less expensive price of ATNPs. As ATNP use leads to significant impacts on physical and mental health, and undeniable negative social influence, aggressive moves in its prevention are needed. Moreover, the strategies should be tailored to the ATNP types given the differences in the biochemical con- 
tent and misconceptions related to these products.

\section{CONFLICT OF INTEREST}

No potential conflict of interest relevant to this article was reported.

\section{ACKNOWLEDGMENTS}

This research received financial support from Universiti Sains Malaysia short-term grant (Grant no., USM/PPSP/61313209).

\section{ORCID}

Nurul Azreen Yusof: https://orcid.org/0000-0002-6418-0659

Faridah Mohd Zin: https://orcid.org/0000-0002-7014-4347

Nur Suhaila Idris: https://orcid.org/0000-0002-5877-061X

Rosediani Mohammad: https://orcid.org/0000-0002-8393-7899

\section{REFERENCES}

1. Institute of Public Health. Global Adult Tobacco Survey Malaysia (GATS) Malaysia 2011. Kuala Lumpur: Institute for Public Health, National Institute of Health, Ministry of Health; 2011.

2. Alderete E, Kaplan CP, Gregorich SE, Perez-Stable EJ. Use of alternative tobacco products in multiethnic youth from Jujuy, Argentina. J Environ Public Health 2010;2010:795265.

3. Institute for Public Health. Tobacco \& E-cigarette Survey among Malaysian Adolescents (TECMA). Putrajaya: Ministry of Health Malaysia; 2016.

4. Shafagoj YA, Mohammed FI, Hadidi KA. Hubble-bubble (water pipe) smoking: levels of nicotine and cotinine in plasma, saliva and urine. Int J Clin Pharmacol Ther 2002;40:249-55.

5. O'Connor RJ. Non-cigarette tobacco products: what have we learnt and where are we headed? Tob Control 2012;21:181-90.

6. Czoli CD, Hammond D, Reid JL, Cole AG, Leatherdale ST. Use of conventional and alternative tobacco and nicotine products among a sample of Canadian youth. J Adolesc Health 2015;57:123-5.

7. Hummel K, Hoving C, Nagelhout GE, de Vries H, van den Putte B, Candel MJ, et al. Prevalence and reasons for use of electronic cigarettes among smokers: findings from the International Tobacco Control (ITC) Netherlands Survey. Int J Drug Policy 2015;26:601-8.

8. Palazzolo DL. Electronic cigarettes and vaping: a new challenge in clinical medicine and public health: a literature review. Front Public Health 2013;1:56.

9. Etter JF. Electronic cigarettes: a survey of users. BMC Public Health 2010;10:231.

10. Li J, Newcombe R, Walton D. The prevalence, correlates and reasons for using electronic cigarettes among New Zealand adults. Addict Behav 2015;45:245-51.

11. Wong LP, Mohamad Shakir SM, Alias H, Aghamohammadi N, Hoe VC. Reasons for using electronic cigarettes and intentions to quit among electronic cigarette users in Malaysia. J Community Health 2016;41: $1101-9$.
12. Wong LP, Alias H, Aghamohammadi N, Aghazadeh S, Hoe VC. Shisha smoking practices, use reasons, attitudes, health effects and intentions to quit among shisha smokers in Malaysia. Int J Environ Res Public Health 2016;13:E726.

13. Goniewicz ML, Lingas EO, Hajek P. Patterns of electronic cigarette use and user beliefs about their safety and benefits: an internet survey. Drug Alcohol Rev 2013;32:133-40.

14. Singh SK, Enzhong L, Reidpath DD, Allotey P. Shisha (waterpipe) smoking initiation among youth in Malaysia and global perspective: a scoping review (2006-2015). Public Health 2017;144:78-85.

15. Al-Naggar RA, Saghir FS. Water pipe (shisha) smoking and associated factors among Malaysian university students. Asian Pac J Cancer Prev 2011;12:3041-7.

16. Martinasek MP, McDermott RJ, Martini L. Waterpipe (hookah) tobacco smoking among youth. Curr Probl Pediatr Adolesc Health Care 2011;41:34-57.

17. Nakkash RT, Khalil J, Afifi RA. The rise in narghile (shisha, hookah) waterpipe tobacco smoking: a qualitative study of perceptions of smokers and non smokers. BMC Public Health 2011;11:315.

18. Khor PY, Harun NB, Ishak FB, Mohd Anuar NA, Abdul Karim N, Azman A, et al. Contributory factors to the smoking of shisha among teenagers in the Perak City of Ipoh: a preliminary qualitative survey. Int J Public Health Res 2012;2:80-4.

19. Kong G, Morean ME, Cavallo DA, Camenga DR, Krishnan-Sarin S. Reasons for electronic cigarette experimentation and discontinuation among adolescents and young adults. Nicotine Tob Res 2015;17:84754.

20. Ministry of Health Malaysia. Clinical practice guidelines treatment of tobacco use disorder. [place unknown]: Tobacco Control Unit \& FCTC Secretariat; 2016 .

21. Centers for Disease Control and Prevention. Global Youth Tobacco Survey 1999-2008: technical report. Atlanta (GA): Centers for Disease Control and Prevention; 2009.

22. Centers for Disease Control and Prevention (CDC). Tobacco product use among middle and high school students: United States, 2011 and 2012. MMWR Morb Mortal Wkly Rep 2013;62:893-7.

23. Enofe N, Berg CJ, Nehl EJ. Alternative tobacco use among college students: who is at highest risk? Am J Health Behav 2014;38:180-9.

24. Gilreath TD, Leventhal A, Barrington-Trimis JL, Unger JB, Cruz TB, Berhane K, et al. Patterns of alternative tobacco product use: emergence of hookah and e-cigarettes as preferred products amongst youth. J Adolesc Health 2016;58:181-5.

25. Sutfin EL, McCoy TP, Morrell HE, Hoeppner BB, Wolfson M. Electronic cigarette use by college students. Drug Alcohol Depend 2013;131:21421.

26. Chang FC, Lee CM, Lai HR, Chiang JT, Lee PH, Chen WJ. Social influences and self-efficacy as predictors of youth smoking initiation and cessation: a 3-year longitudinal study of vocational high school students in Taiwan. Addiction 2006;101:1645-55.

27. The International Tobacco Control Policy Evaluation Project. ITC Malaysia national report: findings from wave 1 to 4 surveys (2005-2009). Waterloo (ON): University of Waterloo, Universiti Sains Malaysia, Ministry of Health Malaysia; 2012.

28. Vartiainen E, Pennanen M, Haukkala A, Dijk F, Lehtovuori R, de Vries $\mathrm{H}$. The effects of a three-year smoking prevention programme in sec- 
ondary schools in Helsinki. Eur J Public Health 2007;17:249-56.

29. Anand V, McGinty KL, O'Brien K, Guenthner G, Hahn E, Martin CA. Ecigarette use and beliefs among urban public high school students in North Carolina. J Adolesc Health 2015;57:46-51.

30. Hiemstra M, Otten R, de Leeuw RN, van Schayck OC, Engels RC. The changing role of self-efficacy in adolescent smoking initiation. J Adolesc Health 2011;48:597-603.

31. Cohen RY, Sattler J, Felix MR, Brownell KD. Experimentation with smokeless tobacco and cigarettes by children and adolescents: relationship to beliefs, peer use, and parental use. Am J Public Health 1987;77:1454-6.

32. Karimy M, Niknami S, Heidarnia AR, Hajizadeh E, Shamsi M. Refusal self efficacy, self esteem, smoking refusal skills and water pipe (Hookah) smoking among iranian male adolescents. Asian Pac J Cancer Prev 2013;14:7283-8.

33. Dobbs PD, Hammig B, Henry LJ. E-cigarette use among US adolescents: perceptions of relative addiction and harm. Health Educ J 2017;76:293-301.

34. Dutra LM, Glantz SA. Electronic cigarettes and conventional cigarette use among U.S. adolescents: a cross-sectional study. JAMA Pediatr 2014;168:610-7.

35. Popova L, Ling PM. Alternative tobacco product use and smoking cessation: a national study. Am J Public Health 2013;103:923-30. 